\title{
Spatial genetic structure across a hybrid zone between European rabbit subspecies
}

The Iberian Peninsula is the only region in the world where the two existing subspecies of the European rabbit (Oryctolagus cuniculus) naturally occur and hybridize. In this study we explore the relative roles of historical and contemporary processes in shaping the spatial genetic structure of the rabbit across its native distribution range, and how they differently affect each subspecies and the hybrid zone. For that purpose multilocus genotypes and mitochondrial DNA data were obtained for 771 rabbits across most of the species' distribution range in Spain. Nuclear markers defined a hierarchical genetic structure firstly comprised by two genetic groups, largely congruent with the mitochondrial lineages and subspecies distributions (O. c. algirus and O. c. cuniculus), which were subsequently subdivided into seven genetic groups probably shaped by environmental or ecological factors. Geographic distance alone emerged as an important factor explaining genetic differentiation across the whole range, without the need to invoke for the effect for geographical barriers. Thus, when considering the overall genetic structure, differences at a local level seem to be of greater importance. The significantly positive spatial correlation up to a distance of only $100 \mathrm{~km}$ supported this hypothesis. However, northern populations of O. c. cuniculus showed more spatial genetic structure and differentiation than O. c. algirus, which could be due to local geographic barriers, limited resources, soil type and/or social behaviours limiting dispersal. The hybrid zone showed similar genetic structure to the southern populations but a larger introgression from the northern lineage genome. These differences have been attributed to selection against the hybrids rather than to behavioural differences between subspecies. Ultimately, the genetic structure of the rabbit in its native distribution range is the result of an ensemble of factors, from geographical and ecological, to behavioural and molecular, that 
hierarchically interact in time and space. 
1 Fernando ALDA ${ }^{1,2^{*}}$, Ignacio DOADRIO ${ }^{1}$

2 'Dpto. Biodiversidad y Biología Evolutiva, Museo Nacional de Ciencias Naturales (CSIC), 3 Madrid, 28006, Spain

$4{ }^{2}$ Current address: Center for Bioenvironmental Research, Tulane University, New Orleans, 5 Louisiana, 70118, USA

6 Corresponding author:

7 Fernando ALDA

8 Center for Bioenvironmental Research (CBR)

9 Tulane University

10 New Orleans, LA 70118, USA

11 Tel: (+1) 5048628441

12 Fax: (+1) 5048628455

13 e-mail: alda.fernando@gmail.com 


\section{INTRODUCTION}

15 In most species populations are genetically structured. This genetic structure may be a

16 consequence of many factors. Foremost among these, geographical factors may lead to vicariant

17 events and divide populations (Knowles \& Carstens, 2007), or ecological factors may determine

18 habitat suitability across space, and consequently population connectivity (Pilot et al., 2006).

19 Behavioral traits can also shape the population structure of species, such as family groups in

20 primates, or colonies of social insects (Shoemaker \& Ross, 1996; Bradley et al., 2002). Finally,

21 genetic structure will also result from the balance between gene flow, drift, and the time

22 necessary to reach a balance between both forces (Hutchison \& Templeton, 1999).

23 The processes leading to population structure can act at different temporal and spatial scales.

24 Temporarily, historical processes such as isolation in glacial refugia and subsequent expansions

25 can leave detectable signals in the current populations (Avise, 2000), as well as contemporary

26 dispersal (Palsboll, 1999). Spatially, gene flow may vary among individuals within a

27 geographical region, between adjacent regions, or at larger scales, between populations that

28 presumably have little genetic exchange but share a more ancient genetic history. Thus,

29 investigating population relationships and their spatial patterns of genetic variation is useful in

30 order to infer these hierarchical and interacting processes (Hedrick, 2005).

31 The European rabbit (Oryctolagus cuniculus Linnaeus 1758) is a species with worldwide

32 biological and economic importance that has long attracted scientific interest (reviewed in

33 Ferreira, 2012). This, along with a well-documented history, has allowed the development of

34 multiple studies on the evolutionary history of this lagomorph from a wide range of molecular 
35 (Ferrand, 1989; Biju-Duval et al., 1991; Branco, Ferrand \& Monnerot, 2000; Geraldes et al.,

36 2008; Carneiro et al., 2012), temporal (Hardy et al., 1994; Monnerot et al., 1994) and

37 geographical perspectives (Webb et al., 1995; Fuller, Wilson \& Mather, 1997; Surridge et al.,

38 1999b; Queney et al., 2000; Queney et al., 2001; Branco et al., 2002).

39 In the Iberian Peninsula, two divergent evolutionary lineages occur and contact each other in the

40 middle of their distribution range (Branco, Ferrand \& Monnerot, 2000; Branco et al., 2002).

41 Studies conducted on uniparentally inherited molecular markers support the existence of two

42 highly differentiated groups: so-called mitochondrial lineage A, predominant in the subspecies $O$.

43 c. algirus (Loche 1867) inhabiting the southwest of the Iberian Peninsula, and lineage B, which

44 predominates in O. c. cuniculus in the northeast of the Peninsula (Biju-Duval et al., 1991). It is

45 proposed that mitochondrial lineages $\mathrm{A}$ and $\mathrm{B}$ diverged following isolation in two glacial refugia

46 in the southwestern and northeastern extremes of the Iberian Peninsula, likely during the

47 Quaternary paleoclimatic oscillations. After climatic amelioration, they expanded their ranges

48 and came again into contact to form a secondary contact zone where they hybridize along a

49 northwest-southeast axis (Branco, Ferrand \& Monnerot, 2000; Branco et al., 2002; Geraldes,

50 Rogel-Gaillard \& Ferrand, 2005; Geraldes, Ferrand \& Nachman, 2006; Ferrand \& Branco, 2007).

51 Hybrid zones like this one are usually interpreted as zones where genetically distinct populations

52 meet and interbreed because, despite genetic differences, they have not reached the status of

53 species and are to some extent interfertile. Therefore, they can be considered as intermediate

54 stages in the process of speciation (Barton \& Hewitt, 1989; Harrison, 1993). Hybrid zones may

55 be ephemeral, resulting from the recent meeting and blending of two divergent lineages, or may 
56 have arisen from an ancient contact and last indefinitely. In the former case, many individuals in

57 the center of the zone will resemble the parental forms, leading to high genetic variance and high

58 linkage disequilibrium between loci. In the latter case, the hybrid zone will consists of individuals

59 that are product of many generations of hybridization, leading to lower genetic variance and

60 lower linkage disequilibrium (Brelsford \& Irwin, 2009). Therefore, the comparative study of the

61 genetic structure in a hybrid zone and in the parental populations can provide insights into the

62 evolutionary processes that contribute to its origin and maintenance (Harrison, 1993).

$63 \mathrm{H}$ ybrid zones are areas of particular interest for evolutionary studies enabling insight into the

64 initial stages of speciation and reproductive isolation, adaptation and selection, and even

65 behavioral processes (Hewitt, 1988; Barton \& Gale, 1993; Arnold, 1997; Futuyma, 1998). In the

66 European rabbit, extensive studies in the hybrid zone have evidenced highly contrasting degrees

67 of introgression among loci, or even a complete absence of genetic structure (Branco, Machado

68 \& Ferrand, 1999; Queney et al., 2001; Geraldes, Ferrand \& Nachman, 2006; Ferrand \& Branco,

69 2007; Campos, Storz \& Ferrand, 2008; Carneiro, Ferrand \& Nachman, 2009; Carneiro et al.,

70 2010; Carneiro et al., 2013). The variation in the introgression of autosomal and sexual

71 chromosomes has also revealed different selective pressures across genes and its importance in

72 the reproductive isolation between the two rabbit subspecies (Geraldes, Ferrand \& Nachman,

73 2006; Campos, Storz \& Ferrand, 2008; Carneiro, Ferrand \& Nachman, 2009; Carneiro et al.,

74 2010; Carneiro et al., 2013).

75 However, differences in the spatial genetic structure between the parental lineages, either in

76 allopatry or interacting within the hybrid zone, are still largely unknown, because most 
77 population genetics studies on the rabbit in the Iberian Peninsula have either examined genetic

78 variation between lineages, or the area where they come into contact (Monnerot et al., 1994;

79 Queney et al., 2001; Branco \& Ferrand, 2003; Ferrand \& Branco, 2007; Carneiro, Ferrand \&

80 Nachman, 2009; Carneiro et al., 2010), but rarely all together or in a comparative context.

81 Furthermore, so far, studies relating the observed genetic structure to behavioral traits or habitat

82 have only been carried out in regions where the rabbit is a non-native species (Fuller, Wilson \&

83 Mather, 1997; Surridge et al., 1999a; Surridge et al., 1999b). In this context, the Iberian Peninsula

84 is unique, since it is the only region in the world where the two subspecies are native and co-

85 occur. Therefore, due to its long evolutionary history in this region, it is expected that a complex

86 ensemble of interacting factors affect the genetic structure of the rabbit at different hierarchical

87 scales.

88 Thus the main objective of this study was to describe and study the relative roles that historical

89 and contemporary processes have in: (1) shaping the spatial genetic structure of the rabbit in

90 Spain, and (2) determining the differences in genetic variability and structure between

91 populations of O. c. cuniculus, O. c. algirus and the hybrid zone.

\section{MATERIALS AND METHODS}

\section{Sample collection}

94 Samples of 771 European rabbits were obtained from 30 localities covering most of their range in

95 Spain (Supplementary Table 1 and Fig. 1). Sampling was performed mainly on hunting estates by 
96 licensed hunters during legal hunting seasons, or during management or restocking activities

97 carried out by local administrations. (Since these activities did not involve any experimental or

98 scientific purpose, no approval was requested from the Ethics Committee at the Spanish Superior

99 Research Council (CSIC)).

100 The number of samples per locality ranged from 2 to 56 individuals (Supplementary Table 1).

101 According to their geographic location (Branco et al., 2002; Geraldes et al., 2008), 6 localities ( $n$ $102=144)$ were a priori assigned to subspecies $O$. c. cuniculus, 14 localities $(n=410)$ to subspecies 103 O. c. algirus, and 10 localities $(n=217)$ to the hybrid zone (Fig. 1, Supplementary Table 1).

104 DNA extraction and amplification of molecular markers

105 Samples obtained from live rabbits consisted of blood drawn from the femoral vein or a small

106 piece of ear tissue. Ear tissue or muscle samples were taken from dead rabbits, depending on the

107 preservation state of the animal. DNA was extracted using the QIAamp DNA Mini Kit

108 (QIAGEN) following the manufacturer's instructions.

109 Mitochondrial lineages, A or B, were identified in all samples by amplifying the complete

110 cytochrome $b$ gene using the primers OcunCB_F: 5'-ATGACCAACATTCGCAAAACC-3' and

111 OcunCB_R: 5'-TGTCTCAGGGAGAACTATCTCC-3'. The PCR reaction was performed in a

112 final volume of $25 \mu \mathrm{L}$ containing: $200 \mu \mathrm{M}$ of dNTPs, $0.2 \mu \mathrm{M}$ of each primer, $1 \mathrm{U}$ Taq polymerase

113 (Eppendorf), 1x PCR buffer (500 mM KCl, $100 \mathrm{mM}$ Tris-HCl pH8.3, $15 \mathrm{mM} \mathrm{Mg}^{2+}$ ), and $1 \mu \mathrm{L}$ of

114 DNA extract. The PCR program consisted of 4 min of denaturation at $94{ }^{\circ} \mathrm{C}$, followed by 40 
115 cycles of $1 \mathrm{~min}$ at $94{ }^{\circ} \mathrm{C}, 1 \mathrm{~min}$ at $55^{\circ} \mathrm{C}$ and $1 \mathrm{~min} 30 \mathrm{~s}$ at $72{ }^{\circ} \mathrm{C}$, plus a final extension of $10 \mathrm{~min}$

116 at $72{ }^{\circ} \mathrm{C}$. PCR products were digested separately with HaeIII and AluI restriction enzymes

117 (Promega) and migrated in 3\% agarose gels stained with ethidium bromide for subsequent

118 visualization under UV light. RFLP patterns were identified as described previously (Branco,

119 Ferrand \& Monnerot, 2000) and the samples were assigned to one of two mitochondrial lineages.

120 All individuals were genotyped according to 10 microsatellite markers: Sat3, Sat4, Sat5, Sat7,

121 Sat8, Sat12, Sat13, Sat16, Sol33 and Sol44 (Mougel, Mounolou \& Monnerot, 1997; Surridge et

122 al., 1997). PCR reactions were performed in a final volume of $13 \mu \mathrm{L}$ that contained $200 \mu \mathrm{M}$

$123 \mathrm{dNTPs}, 0.2-0.4 \mu \mathrm{M}$ of each primer, 2-2.5 $\mathrm{mM} \mathrm{MgCl}_{2}, 0.325 \mathrm{U}$ Taq polymerase (Eppendorf), $1 \mathrm{x}$

124 PCR buffer (500 mM KCl, $100 \mathrm{mM}$ Tris-HCl pH 8.3), and $0.5 \mu \mathrm{L}$ of DNA extract. PCR programs

125 involved $2 \mathrm{~min}$ of initial denaturation at $95^{\circ} \mathrm{C}$, followed by 35 cycles of $30 \mathrm{sec}$ at $95^{\circ} \mathrm{C}, 30 \mathrm{sec}$

126 between $55^{\circ} \mathrm{C}$ and $65^{\circ} \mathrm{C}, 30 \mathrm{sec}$ at $72{ }^{\circ} \mathrm{C}$, followed by a final extension step of $7 \mathrm{~min}$ at $72{ }^{\circ} \mathrm{C}$.

127 The amplified fragments were analyzed in an ABI3730 automatic sequencer (Applied

128 Biosystems) and allele sizes were assigned using the program GeneMapper v3.7 (Applied

129 Biosystems). The complete data file of microsatellite genotypes and mitochondrial haplotypes

130 was deposited as a Supplementary Dataset in PeerJ.

\section{Statistical analyses}

132 Our first objective was to undertake a formal analysis on the genetic structure of the two rabbit

133 lineages and across the hybrid zone between the lineages. For this purpose, we used Bayesian

134 model-based assignment methods to determine admixture proportions in our rabbit sample.

135 Although we were primarily interested in a model with two clusters for assessing admixture 
136 between lineages, we also analyzed whether models with more than two clusters were supported

137 by our data. Therefore, firstly we used the algorithm of STRUCTURE 2.2 (Pritchard, Stephens \&

138 Donnelly, 2000) implementing the admixture model with correlated allele frequencies (Falush,

139 Stephens \& Pritchard, 2003), since this model is more appropriate for individuals with admixed

140 ancestries and for populations with similar expected frequencies. No information on the localities

141 of origin of individuals was included. Ten independent analyses were run for each value of $K$,

142 from $K=1$ to $K=30$. Each analysis consisted of $1 \times 10^{6}$ Markov chains with a prior burn-in of 1

$143 \times 10^{5}$ chains. Mean posterior probability values were used to calculate $\Delta K$, a measure of the rate

144 of change of the posterior probabilities between successive $K$ values. Thus, it is possible to detect

145 when the increase in $\ln P(X \mid D)$ is not significant anymore and find the true value of $K$ (Evanno,

146 Regnaut \& Goudet, 2005).

147 To visually explore the distribution of the inferred genetic groups across the hybrid zone, the

148 proportion of genetic admixture and the frequency of each mitochondrial lineage were plotted

149 along a one-dimensional transect perpendicular to the proposed rabbit hybrid zone (Branco,

150 Ferrand \& Monnerot, 2000; Branco et al., 2002; Geraldes et al., 2008), with the exception of the

151 localities of Galicia and Mallorca which were excluded (Fig. 1). We considered km 0 of the

152 linear transect to be the approximate intersection between the transect that the hybrid zone (Fig.

153 1). Geographical locations along this linear transect were fitted to a sigmoid curve (3 parameters)

154 as expected by hybrid zone tension zone models (Barton \& Hewitt, 1985; Barton \& Gale, 1993)

155 in SigmaPlot 10.0 (Systat Software, Inc.). Additionally, congruence between the assignment

156 probabilities and the frequency of mitochondrial lineages was evaluated by performing $c^{2}$ tests in

157 both parental lineages and in the hybrid zone. 
158 Secondly, we used the Bayesian method implemented in the program BAPS 5.1 (Corander \&

159 Marttinen, 2006). In addition to the genetic data, we included the geographical coordinates of

160 each individual and used the spatial model in BAPS (Corander, Sirén \& Arjas, 2008). This model

161 estimates genetic structure assuming that the structure within a particular area depends on the

162 neighboring areas, thereby increasing the statistical power to detect the true genetic structure

163 (Corander, Sirén \& Arjas, 2008). We undertook 10 independent replicates from 1 to a maximum

164 of 30 genetic clusters. The average admixture values obtained for each individual were plotted

165 using the maps package in $\mathrm{R}$ (R Core Team, 2014).

166 For the inferred genetic clusters and the localities analyzed with more than 10 sampled

167 individuals, we tested significant deviations from Hardy-Weinberg equilibrium through a Fisher

168 exact test (Guo \& Thompson, 1992) after applying the Bonferroni correction (Rice, 1989) in

169 GENEPOP 3.4 (Raymond \& Rousset, 1995). We calculated parameters of genetic diversity such

170 as number of alleles $\left(N_{A}\right)$, allelic richness $\left(A_{R}\right)$, observed and expected heterozygosity $\left(H_{o}\right.$ and $\left.H_{e}\right)$

171 and inbreeding coefficient $\left(F_{I S}\right)$ for each locus and genetic group using the programs GENETIX

1724.02 (Belkhir et al., 2004) and FSTAT 2.9.3 (Goudet, 1995).

173 The distribution of genetic variation among the sampled localities, as well as within and among

174 the inferred genetic groups was assessed by an analysis of molecular variance (AMOVA)

175 (Excoffier, Smouse \& Quattro, 1992). AMOVA was performed using GenoDive 2.0b11

176 (Meirmans \& Van Tienderen, 2004) which allows the calculation of a $F_{S T}$ analogue coefficient of

177 differentiation, standardized according to the level of intra-population variation, so that the 
178 results obtained can be compared between markers showing different polymorphism (Meirmans,

179 2006). To avoid confusion, this ratio is hereafter referred to as $F_{S T}$ '.

180 The effect of geographical distance on the genetic differentiation between individuals was also

181 tested for all the samples in peninsular Spain (i.e. excluding the population from the island of

182 Mallorca) and for each lineage and the hybrid zone separately. Regression was performed for the

183 kinship coefficient between pairs of individuals $\left(f_{\mathrm{ij}}\right)$ (Loiselle et al., 1995) and their geographical

184 distance $\left(d_{\mathrm{ij}}\right)$, to give a regression slope $\ln b_{d}$ and its statistical significance (Vekemans \& Hardy,

185 2004). Also, spatial autocorrelation methods were applied to examine spatial genetic structure

186 (Smouse \& Peakall, 1999). Geographic locations of individuals were permuted 10,000 times

187 among 50 distance intervals with an equal number of comparisons between individuals (5935) to

188 test the null hypothesis that $d_{\mathrm{ij}}$ and $f_{\mathrm{ij}}$ were not correlated. Positive spatial autocorrelations are

189 expected when gene flow is restricted to short distances. These tests are dependent on the type

190 and scale of sampling (Vekemans \& Hardy, 2004), so to compare the extent of spatial genetic

191 structure in each subspecies of rabbit and the hybrid zone, we used the statistical $S p$ (Vekemans \&

192 Hardy, 2004), $S p=-\ln b_{d} /\left(1-F_{\mathrm{ij}}\right)$, where $F_{\mathrm{ij}}$ is the average kinship coefficient between individuals

193 closer together (the first distance interval, $\sim 5 \mathrm{~km}$ ), and $\ln b_{d}$ is the slope of the linear regression of

194 the correlation coefficients and the logarithm of the geographical distance. All these tests were

195 conducted in SPAGeDi 1.2 (Hardy \& Vekemans, 2002). Additionally, a Mantel test (Mantel,

196 1967) was employed to determine if there was significant correlation between the genetic $\left(F_{S T} / 1\right.$ -

$\left.197 F_{S T}\right)$ and geographical distances of the localities studied. Also, the presence or absence of putative

198 barriers, such as large rivers and/or mountain ranges, between localities was coded as 1 and 0 in a

199 third data matrix. Using these three distance matrices, a partial Mantel test was performed to 
200 determine whether, besides geographical distance, these landforms represented a barrier to gene

201 flow for the rabbit. Both analyses were performed in ARLEQUIN 3.1.

\section{RESULTS}

203 Distribution of genetic diversity

204 Overall, similar proportions of rabbits carried mitochondrial haplotypes from lineages A and B 205 (53.5\% and 46.5\% respectively). In only five localities with over 10 individuals analyzed, all 206 individuals belonged to one lineage. Rabbits from Mallorca, Lérida and Galicia belonged to

207 lineage B, while those from Jaén3 and Sevilla1 belonged to lineage A. Although all the other 208 localities showed a mixture of both lineages, there was a clear predominance of B haplotypes in 209 the northeast of the Iberian Peninsula and Balearic islands, A haplotypes in the southwest, and a 210 mixture of both in the center of the Peninsula (Table 1).

211 In general, nuclear genetic diversity was high, with a total of 264 alleles at the 10 microsatellites

212 analyzed (average $N_{A}$ per locus $=26.29 \pm 9.07$ ). In all localities heterozygosity values were larger

213 than $H_{o}=0.6$ (average $H_{o}=0.7 \pm 0.15$ ). The localities showing greatest diversity, measured as

214 allelic richness, were Madrid1 and Sevilla2 $\left(A_{R}=7.70\right.$ and 7.62), whereas the least diverse were

215 Mallorca $\left(A_{R}=5.15\right)$ and La Rioja $\left(A_{R}=6.20\right)$ (Table 1 and Supplementary Table 2$)$. 
216 Deviations from Hardy-Weinberg equilibrium were detected in 17 of the 26 locations analyzed

217 (Table 1 and Supplementary Table 2). In all cases, these deviations were due to heterozygote

218 deficits. Locations in the center and southwest of the Iberian Peninsula showed larger deviations

219 from equilibrium, mainly attributed to locus Sat16 and to a lesser extent to Sat3 and Sol33.

220 Interestingly, none of these loci appeared to be in disequilibrium in the northeastern localities. A

221 comparison of the observed genotypes with a random distribution of genotypes generated by

222 MICRO-CHECKER (van Oosterhout et al., 2004) suggested the presence of null alleles at locus

223 Sat16, as had been proposed earlier for this microsatellite (Queney et al., 2001).

\section{Structure and assignment of rabbit genetic clusters}

225 The Bayesian clustering analysis performed in STRUCTURE revealed that $\ln P(X \mid D)$ increased

226 substantially from $K=1$ to $K=2$ and then was attenuated as the number of $K$ increased but

227 without reaching a clear asymptote. Notwithstanding, calculation of $\Delta K$ clearly revealed the

228 existence of 2 genetic populations or groups (K1 and K2). Taken together, these results suggest

229 that the sampled rabbits belong to two large and distinct genetic groups, but do not completely

230 exclude the possibility that more gene pools exist. The distribution of the two genetic groups

231 exhibited high geographical correlation such that the localities to the south of the Iberian

232 Peninsula were assigned with a greater likelihood to group K1 and the northern localities to K2

233 group (Table 2 and Figs. 2 and 3).

234 Both the assignment probabilities to the genetic groups based on the nuclear DNA and the

235 frequencies of mitochondrial lineages closely conformed to sigmoidal functions $\left(R^{2}=0.878, F=\right.$

$23657.478, P<0.0001$ for the microsatellite data; $R^{2}=0.628, F=13.501, P<0.0001$ for the mtDNA 
237 data; Fig. 3). In addition, the inferred genetic groups were in agreement with the mitochondrial

238 haplotypes of each individual. Of the 224 individuals assigned to K1with a posterior probability

239 greater than $0.9,91 \%$ carried mitochondrial haplotypes belonging to lineage $\mathrm{A}$, while $82 \%$ of the

240239 rabbits assigned with equal probability to K2 showed haplotypes from lineage B (Fig. 2).

241 Thus, the frequency of mitochondrial haplotypes in the parental lineages did not differ

242 significantly from the individuals' assignment frequencies to the inferred genetic groups $\left(\square^{2}=\right.$

$2430.781, \mathrm{df}=1, P=0.377)$.

244 The analysis in BAPS of the genetic data together with individual geographical information,

245 detected a maximum marginal likelihood (corresponding to the maximum posterior probability)

246 for 7 genetic clusters. Most of the inferred genetic clusters showed a well-defined geographical

247 distribution (Table 2 and Fig. 1). The first cluster corresponded to all individuals from the

248 Balearic Islands (K-BAL). In the north of the Iberian Peninsula, a second cluster appeared

249 consisting mainly of individuals from Lérida (K-NE) and a third cluster comprising individuals

250 from the localities of La Rioja, Madrid1 and Madrid2 (K-N). In the south of the Iberian

251 Peninsula, one large cluster was inferred, that included most of the individuals from Badajoz1,

252 Badajoz2, Jaén2, Sevilla1, Sevilla2 and Cádiz (K-S1), and a small group of individuals from

253 Sevilla2 (K-S2). At the heart of the Iberian Peninsula we found a large cluster fully or partially

254 covering the localities of Galicia, Valladolid, Madrid1-3, Cuenca, Toledo1-6, Albacete, Ciudad

255 Real1-3 and Cáceres1 and Cáceres2 (K-ZH) and another small group of individuals from the

256 locality of Cuenca (K-CU) (Table 2 and Fig. 1). Also, these clusters were congruent with the

257 genetic groups inferred in STRUCTURE and with the mitochondrial haplotypes of the

258 individuals, so that the northern and central clusters (K-BAL, K-NE, K-N and K-CU) had 
259 assignment probabilities greater than $90 \%$ to K2, and in the same way, the southern clusters (K-

260 S1 and K-S2) to K1.

261 Genetic diversity parameters estimated for the inferred genetic clusters in BAPS, indicated a

262 greater diversity for K-ZH and K-S1, which were also the only clusters in Hardy-Weinberg

263 disequilibrium, due to a significant deficit of heterozygotes (Table 2 and Supplementary Table 3).

264 All genetic clusters displayed unique alleles, which were usually found at low frequencies. In

265 those genetic clusters that mostly include lineage A rabbits (K-S1 and K-S2), 37 unique alleles

266 were found. While clusters that mostly include lineage B rabbits (K-BAL, K-NE, KN and K-CU)

267 showed 21 unique alleles. Forty-nine unique alleles were detected in cluster K-ZH.

268 The percentage of genetic variation explained by the 7 genetic clusters was similar, but not 269 greater than that obtained among all localities $\left(F_{S T^{\prime}}=0.325, P<0.001, F_{S T}{ }^{\prime}=0.370, P<0.001\right.$, 270 respectively). Conversely, $R_{S T}$ was much higher $\left(R_{S T}=0.627, P<0.001\right.$ and $R_{S T}=0.110, P<$

2710.001 , respectively), indicating that the effect of mutation is of greater importance than drift in 272 the differentiation of rabbit genetic clusters.

273 The Mantel test revealed significant correlation between geographical distances and genetic

274 distances for all pairs of populations ( $r=0.538, P<0.001$, Fig. 4). However, this correlation was

275 not improved by including the effect of geographical barriers, such as rivers or mountain ranges,

276 in the partial Mantel test. Across the whole distribution of rabbits in peninsular Spain, the

277 regression slope between kinship and geographical distance was negative and statistically 
278 significant $\left(\ln b_{d}=-0.011, P<0.001\right)$. Relationships between individuals decreased rapidly as

279 geographical distances increased and this autocorrelation was significantly positive up to a

280 distance of approximately $100 \mathrm{~km}$ (Fig. 5A). By comparing the spatial genetic structure of the

281 two subspecies of rabbit and those of the hybrid zone, spatial autocorrelation analyses indicated

282 much higher $f_{i j}$ values and a steeper decline of kinship with distance in O. c. cuniculus for the first

283 distance intervals. Similarly, we obtained a higher $S p$ value for $O$. c. cuniculus $(S p=0.0137)$ than

284 for $O$. c. algirus and the hybrid zone, which showed similar values $(S p=0.0062$ and $S p=0.0063$, 285 respectively), indicating a greater genetic structure of rabbit populations in the northeast of the 286 Iberian Peninsula (Fig. 5B).

\section{DISCUSSION}

\section{Variation in genetic diversity}

289 Overall, the microsatellites analyzed were highly polymorphic, and showed similar variability to

290 that reported for 9 of the 10 loci studied (Queney et al., 2001). The general trend was greater

291 genetic variability in populations from the central Iberian Peninsula and lower diversity in the

292 northeastern mainland populations (Table 1 and Supplementary Table 2). This reduced genetic

293 diversity of northeast populations has been attributed to a lower effective size during their

294 isolation in Quaternary glacial refugia, compared to the southern populations (Branco, Ferrand \&

295 Monnerot, 2000). The lowest diversity and high genetic differentiation found in the island of

296 Mallorca is most likely due to the founder effect caused by the introduction of the rabbit in these

297 Mediterranean islands following the first human arrival to Mallorca 4300-4100 years ago (Flux,

298 1994; Alcover, 2008). Interestingly, a much older estimate has been proposed for the most recent

299 common ancestor between island and mainland rabbits between 170,000 years and present, 
300 according to mitochondrial sequence data (Seixas et al., 2014). While the number of alleles and

301 allelic richness detected for Mallorca were lower than in most of the other samples analyzed, this

302 was not the case for its heterozygosity values (Table 1 and Supplementary Table 2). Loss of

303 heterozygosity depends on the time it takes a population to recover a large size after a bottleneck

304 (Nei, Maruyama \& Chakraborty, 1975). Thus, because of its rapid expansion capability, the

305 European rabbit may have managed to retain more diversity during the different colonizations or

306 bottlenecks suffered (Queney et al., 2000). Similarly, this could explain why in La Rioja, where

307 demographic explosions are frequent, a low number of alleles are detected, but not a low

308 heterozygosity. In contrast, in Galicia, both allelic richness and heterozygosity are low and show

309 a significant excess of homozygotes, since rabbit populations in this region have continuously

310 declined in recent years with the consequent loss of genetic diversity (Table 1 and Supplementary

311 Table 2).

312 Most localities, particularly the southern ones, revealed loci in Hardy-Weinberg

313 disequilibrium, because of a deficiency in heterozygotes. In this study, as in earlier ones (Queney

314 et al., 2001), putative null alleles were detected at Sat16, although the exclusion of this locus and

315 others showing large deviations from equilibrium (e.g. Sat3 and Sol33), did not significantly alter

316 the results. The absence of disequilibrium in the northeastern localities could be explained by the

317 fact that the microsatellites analyzed were originally developed for the domestic rabbit (i.e.

318 subspecies O. c. cuniculus) (Mougel, Mounolou \& Monnerot, 1997; Surridge et al., 1997),

319 therefore a higher chance for null alleles could occur in the southern O. c. algirus. Another non-

320 exclusive explanation for the significant deficit of heterozygotes could be a Wahlund effect. The

321 territorial behavior and social structure of the rabbit (Surridge et al., 1999a; Surridge et al., 
322 1999b) could lead to an underlying genetic structure at a small geographical scale that is not

323 detected by Bayesian clustering methods.

\section{Hierarchical genetic structure dependent on geographic distance}

325 Overall, the European rabbit in Spain showed considerable genetic structure, which was similar

326 to that described for rabbit populations in the northeast and southwest of the Iberian Peninsula

327 (Queney et al., 2001) and slightly lower than that reported for Britain (Surridge et al., 1999a).

328 The fact that the largest percentage of genetic variation was explained separately by each

329 sampling locality indicates that genetic structure exists at a very local scale and reaffirms the

330 importance of rabbit social behavior in shaping its genetic structure (Surridge et al., 1999a).

331 Bayesian methods and AMOVA, as well as comparisons of $F_{S T}$ and $R_{S T}$ statistics, indicate that the

332 rabbit has a hierarchical genetic structure. First, the oldest and largest differences are mainly

333 reflected by the two genetic groups, based on nuclear markers, and their high $R_{S T}$ values. Within

334 these, there are other genetic groups identified in BAPS that are determined by other factors that

335 could be either environmental or ecological. In turn, these inferred populations consist of even

336 smaller groups conditioned by the social behavior of the rabbit, and are reflected by the

337 significant values of $F_{S T}$ between localities and the significantly positive spatial autocorrelation

338 (Lugon-Moulin et al., 1999; Balloux \& Lugon-Moulin, 2002) 
339 In addition to the hierarchical genetic structure of the rabbit in Spain, geographic distance

340 emerged as an important factor explaining genetic differentiation (Figs. 4 and 5). This contradicts

341 the situation in Britain, where significant differences observed between locations could not be

342 correlated with geographical distance (Surridge et al., 1999a). Similarly, it seems logical that

343 main rivers, or other geographical features, constitute a barrier to gene flow in rabbits given their

344 low dispersal capacity (Webb et al., 1995; Richardson et al., 2002). However, these barriers did

345 not determine an increase in genetic differentiation explained solely by geographic distance. This

346 is probably because, when considering the overall genetic structure and distribution of the rabbit,

347 differences at a more local level have greater importance (Surridge et al., 1999a; Surridge et al.,

348 1999b; Branco, Ferrand \& Monnerot, 2000). This hypothesis is further supported by the results of

349 our spatial autocorrelation analyses indicating significantly positive correlation up to a distance

350 of about $100 \mathrm{~km}$ (Fig. 5A). However, the influence of geographic distance on genetic

351 differentiation was not the same for all rabbit populations. Northern populations of $O . c$.

352 cuniculus (K2) showed greater relatedness among close individuals and more spatial genetic

353 structure and differentiation than the southern populations or those in the hybrid zone (Fig. 5B).

354 This contrasting pattern could be due to the existence of genetic barriers among populations

355 within each region. For example, it is well known that the Ebro River, running across

356 northeastern Spain, has historically acted both as a physical and an ecological barrier for mammal

357 species (O'Regan, 2008). The inferred genetics groups of K-NE and K-N are located to the north

358 and south of the Ebro Valley, thus suggesting its role as a current barrier to gene flow (Fig. 1).

359 Conversely, other large rivers in southern Spain (e.g. Guadiana River) do not seem to hinder gene

360 flow among southern rabbit populations. At a smaller geographic scale, low dispersal might also

361 be due both to resource availability and soil type, which largely influence the distribution and 
362 social relationships of rabbits (Baker \& Dunning, 1975; Cowan \& Garson, 1985; Blanco \&

363 Villafuerte, 1993; Richardson et al., 2002; Lombardi et al., 2003) and of other fossorial mammals

364 (Lovegrove, 1989; Ebensperger \& Cofré, 2001). It has been shown for other burrowing species,

365 such as the wombat (Lasiorhinus latifrons), that where soft soils occur the construction of

366 burrows is facilitated so animals do not need to share their shelter with other groups of

367 individuals (Walker, Taylor \& Sunnucks, 2007). Thus, the social structure of wombats in soft

368 soils is characterized by closely related social groups and positive spatial correlation within a

369 short distance, as observed in $O$. c. cuniculus in the northern Iberian Peninsula where softer soils

370 also exist (Blanco \& Villafuerte, 1993). In contrast, in hard soils, wombats share burrows with

371 other individuals, and therefore are less related and spatial correlation is observed at a greater

372 distance (Walker, Taylor \& Sunnucks, 2007), as observed for the southern O. c. algirus

373 populations (Fig. 5B).

\section{Genetic variation within the hybrid zone}

375 The large differences between the two rabbit lineages were evidenced by the maximum $R_{S T}$ value

376 obtained when considering the genetic variation among lineages A and $\mathrm{B}$, which represent a

377 divergence of 1,800,000 years - 2,000,000 (Branco, Ferrand \& Monnerot, 2000; Carneiro,

378 Ferrand \& Nachman, 2009). The transition between these two genetic groups and mitochondrial

379 lineages is well explained by a sigmoid curve. This was consistent with the Bayesian clustering

380 of STRUCTURE, which indicates that the hybrid zone is not formed by individuals with a

381 bimodal distribution of genotypes from the parental lineages, but instead they form a gradual

382 cline of assignment probabilities to each group (Figs. 2 and 3). On the other hand, when

383 geographic information was incorporated in the Bayesian clustering analysis of BAPS, which 
384 usually helps to increase the power of analysis in cases where hierarchical structure might hinder

385 the delineation of discrete groups on a smaller scale (Corander, Sirén \& Arjas, 2008), the hybrid

386 zone was shown as a large genetic cluster itself (Fig. 1). However, this result should be taken

387 cautiously, since it could represent an artifact of the method. Firstly, Bayesian clustering methods

388 can overestimate genetic structure when analyzing scenarios under a pattern of isolation by

389 distance (Frantz et al., 2009), or under strong linkage disequilibrium or departures from Hardy-

390 Weinberg equilibrium (Falush, Stephens \& Pritchard, 2003). Secondly, a kind of mixture linkage

391 disequilibrium can occur even between physically unlinked loci, due to the correlation of allelic

392 frequencies within populations. As a consequence, highly contrasting parental genotypes can lead

393 to differences in this pattern of linkage disequilibrium and intermediate allele frequencies

394 between these populations be interpreted as a distinct genetic cluster (Falush, Stephens \&

395 Pritchard, 2003; Kaeuffer et al., 2007).

396 Notwithstanding, hybrid zones can also be characterized by new genotypic combinations,

397 resulting from the crossing of genetically divergent individuals (Arnold et al., 1999). As expected

398 from a region comprising the gene pool from both lineages of rabbit, the genetic diversity found

399 in the hybrid zone was higher than in the parental populations, as reflected by the total number of

400 alleles, allelic richness and expected heterozygosity (Table 1). Interestingly, the higher number of

401 alleles was mainly due to 49 alleles exclusively observed in this region, as opposed to the 37 and

40221 exclusive alleles found in the parental populations. Though this could simply be the

403 consequence of the higher number of individuals found in this inferred cluster $(n=457)$, it is

404 surprising that the hybrid zone shows so many exclusive alleles, when we would initially expect

405 it to only hold the sum of the parental alleles. Unique alleles have been previously described in

406 the rabbit hybrid zone for the HBA haemoglobin alpha chain gene, which probably originated by 
407 recombination of alleles from the parental lineages (Campos, Storz \& Ferrand, 2008). However,

408 in the case of microsatellite loci, further evidence could suggest that these new alleles might be

409 the result of an increased mutation rate caused by higher heterozygosity of the hybrids (Bradley

410 et al., 1993; Hoffman \& Brown, 1995; Amos \& Harwood, 1998).

411 In the hybrid zone cluster, considered as the region with intermediate frequencies not belonging

412 to any of the parental groups, the genetic contribution of each rabbit lineage was not balanced. In

413 this area, the frequency of the two mitochondrial lineages is virtually the same $(\mathrm{A}=0.485$ and $\mathrm{B}$

$414=0.515)$, but significantly greater proportions of individuals had been assigned to $\mathrm{K} 2(\mathrm{~K} 1=0.37$

415 and $\mathrm{K} 2=0.63)\left(c^{2}=25.187, \mathrm{df}=1, P<0.0001\right)$, showing a greater genetic introgression of

416 lineage $\mathrm{B}$, characteristic of the northern O.c. cuniculus, into lineage A, O.c. algirus, than vice

417 versa. This is consistent with recent findings related to autosomal loci (Carneiro, Ferrand \&

418 Nachman, 2009; Carneiro et al., 2013), yet contrasts with that described for the X chromosome,

419 suggesting slight introgression from the southwest to the northeastern lineages of the Iberian

420 Peninsula (Geraldes, Ferrand \& Nachman, 2006). The fact that the greatest contribution of the

421 northern rabbit lineage is only reflected in the frequencies of nuclear markers and not in those of

422 maternal inheritance could suggest that males are primarily responsible for this bias. If this is the

423 case, it would be expected that the Y chromosome would be more introgressed than autosomal

424 loci. Conversely, it has been evidenced that the Y chromosome cline is highly stepped, as well as

425 the mtDNA, which suggests some kind of selection acting against introgression (Geraldes,

426 Ferrand \& Nachman, 2006; Geraldes et al., 2008; Carneiro et al., 2013). In this regard,

427 preliminary behavioral work discarded the existence of pre-mating reproductive selection

428 between lineages, and found instead lower fertility in F1 males, thus following the expectations

429 of Haldane's rule (Haldane, 1922; Blanco-Aguiar et al., 2010). In this context it seems that the 
430 relative role of selection leading to postzygotic barriers has a stronger importance in shaping the

431 genetic structure in the rabbit hybrid zone than behavioral and prezygotic barriers. Similarly,

432 different types of selection have been detected at several autosomal loci, suggesting a wide range

433 of evolutionary pressures across the rabbit's genome as well as across distribution range in the

434 Iberian Peninsula (Campos, Storz \& Ferrand, 2008; Carneiro et al., 2012; Carneiro et al., 2013).

435 Ultimately, multiple factors ranging from geographical and ecological, to behavioral and

436 molecular, are interacting and shaping the overall genetic structure of the rabbit subspecies and

437 their hybrid zone. Future studies using genomic data coupled with behavioral and ecological

438 information could further clarify how these issues are related to the differences in genetic

439 variation and structure of the rabbit subspecies.

\section{ACKNOWLEDGEMENTS}

441 The authors wish to thank all those who provided samples for this study: the Consellería de

442 Territori i Habitatge from Generalitat Valenciana, the Hunting Federation of Lérida, Hunting

443 Society of Ajalvir (Madrid), M. Sanmartín from the University of Santiago de Compostela, S.

444 Agudín, J. Inogés, J. Layna, F. Leiva, F. Silvestre and specially to F. Guil from Fundación CBD-

445 Habitat. We also thank N. Ferrand and S. Lopes for data reviewing and helpful discussion of the

446 results, as well as two anonymous referees for their thorough revisions. A. Peterson reviewed the

447 English text, L. Alcaraz assisted in the laboratory and A. Benítez-López provided assistance with 448 statistical analyses. 
450 Alcover JA. 2008. The first Mallorcans: prehistoric colonization in the Western Mediterranean.

451 Journal of Prehistory 21:19-84.

452 Amos W, and Harwood J. 1998. Factors affecting levels of genetic diversity in natural 453 populations. Philosophical Transactions of the Royal Society of London Series B-Biological 454 Sciences 353:177-186.

455 Arnold ML. 1997. Natural hybridisation and evolution. New York: Oxford University Press.

456 Arnold ML, Bulger MR, Burke JM, Hempel AL, and Williams JH. 1999. Natural hybridization:

457 how long can you go and still be important? Ecology 80:371-381.

458 Avise JC. 2000. Phylogeography: The history and formation of species. Cambridge, MA: 459 Harvard University Press.

460 Baker AN, and Dunning RA. 1975. Effects of soil type and crop density on the activity and 461 abundance of the epigeic fauna, particularly Carabidae, in sugar-beet fields. The Journal of 462 Applied Ecology 12:809-818.

463 Balloux F, and Lugon-Moulin N. 2002. The estimation of population differentiation with 464 microsatellite markers. Molecular Ecology 11:155-165.

465 Barton N, and Gale KS. 1993. Genetic analysis of hybrid zones. In: Harrison RG, ed. Hybrid 466 Zones and the Evolutionary Process. New York: Oxford University Press.

467 Barton NH, and Hewitt GM. 1985. Analysis of hybrid zones. Annual Review of Ecology and 468 Systematics 16:113-148.

469 Barton NH, and Hewitt GM. 1989. Adaptation, speciation and hybrid zones. Nature 341:497-503.

470 Belkhir K, Borsa P, Chikhi L, Raufaste N, and Bonhomme F. 2004. GENETIX 4.05, logiciel sous 471 Windows ${ }^{T M}$ pour la génétique des populations. Montpellier: Laboratoire Génome, Populations, 472 Interactions, CNRS UMR 5000, Université de Montpellier II.

473 Biju-Duval C, Ennafaa H, Dennebouy N, Monnerot M, Mignotte F, Soriguer RC, El Gaaïed A, El 474 Hili A, and Mounolou JC. 1991. Mitochondrial DNA evolution in lagomorphs: origin of 
475 systematic heteroplasmy and organization of diversity in European rabbits. Journal of Molecular 476 Evolution 33:92-102.

477 Blanco JC, and Villafuerte R. 1993. Factores ecológicos que influyen sobre las poblaciones de 478 conejos. Madrid: Instituto Nacional para la Conservación de la Naturaleza.

479 Blanco-Aguiar JA, Carneiro M, Villafuerte R, Ríos-Saldaña CA, Ferreira C, and Ferrand N. 480 2010. Preliminary results assessing pre and postzygotic isolation between two subspecies,

481 Oryctogalus cuniculus algirus and O.c. cuniculus, of the European rabbit. Trends in Biodiversity 482 and Evolution (TiBE). Vairao, Portugal: Research Centre in Biodiversity and Genetic Resources, 483 University of Porto.

484 Bradley BJ, Bull JJ, Johnson AD, and Hillis DM. 1993. Origin of a novel allele in a mammalian 485 hybrid zone. Proceedings of the National Academy of Sciences of the United States of America 486 90:8939-8941.

487 Bradley BJ, Doran D, Robbins MM, Williamson E, Boesch C, and Vigilant L. 2002. Comparative 488 analyses of genetic social structure in wild gorillas (Gorilla gorilla) using DNA from feces and 489 hair. American Journal of Physical Anthropology:47-48.

490 Branco M, and Ferrand N. 2003. Biochemical and population genetics of the rabbit, Oryctolagus 491 cuniculus, carbonic anhydrases I and II, from the Iberian Peninsula and France. Biochemical 492 Genetics 41:391-404.

493 Branco M, Ferrand N, and Monnerot M. 2000. Phylogeography of the European rabbit 494 (Oryctolagus cuniculus) in the Iberian Peninsula inferred from RFLP analysis of the cytochrome 495 b gene. Heredity 85:307-317.

496 Branco M, Machado JC, and Ferrand N. 1999. Extensive genetic polymorphism of peptidases A, 497 B, C, and D, in wild rabbit (Oryctolagus cuniculus) populations from the Iberian Peninsula. 498 Biochemical Genetics 37:237-249.

499 Branco M, Monnerot M, Ferrand N, and Templeton AR. 2002. Postglacial dispersal of the 500 European rabbit (Oryctolagus cuniculus) on the Iberian Peninsula reconstructed from nested 501 clade and mismatch analyses of mitochondrial DNA genetic variation. Evolution 56:792-803. 
502 Brelsford A, and Irwin DE. 2009. Incipient speciation despite little assortative mating: the

503 yellow-rumped warbler hybrid zone. Evolution 63:3050-3060.

504 Campos R, Storz JF, and Ferrand N. 2008. Evidence for contrasting modes of selection at

505 interacting globin genes in the European rabbit (Oryctolagus cuniculus). Heredity 100:602-609.

506 Carneiro M, Albert FW, Melo-Ferreira J, Galtier N, Gayral P, Blanco-Aguiar JA, Villafuerte R, 507 Nachman MW, and Ferrand N. 2012. Evidence for widespread positive and purifying selection 508 across the European rabbit (Oryctolagus cuniculus) genome. Molecular Biology and Evolution 509 29:1837-1849.

510 Carneiro M, Baird SJE, Afonso S, Ramirez E, Tarroso P, Teotónio H, Villafuerte R, Nachman

511 MW, and Ferrand N. 2013. Steep clines within a highly permeable genome across a hybrid zone 512 between two subspecies of the European rabbit. Molecular Ecology 22:2511-2525.

513 Carneiro M, Blanco-Aguiar JA, Villafuerte R, Ferrand N, and Nachman MW. 2010. Speciation in 514 the European rabbit (Oryctolagus cuniculus): islands of differentiation on the X chromosome and 515 autosomes. Evolution 64:3443-3460.

516 Carneiro M, Ferrand N, and Nachman MW. 2009. Recombination and speciation: loci near

517 centromeres are more differentiated than loci near telomeres between subspecies of the European 518 rabbit (Oryctolagus cuniculus). Genetics 181:593-606.

519 Corander J, and Marttinen P. 2006. Bayesian identification of admixture events using multilocus 520 molecular markers. Molecular Ecology 15:2833-2843.

521 Corander J, Sirén J, and Arjas E. 2008. Bayesian spatial modeling of genetic population structure. 522 Computational Statistics 23:111-129.

523 Cowan DP, and Garson PJ. 1985. Variations in the social structure of rabbit populations: causes 524 and demographic consequences. In: Smith RM, and Sibly RH, eds. Behavioural Ecology:

525 Ecological Consequences of Adaptive Behaviour The 25th Symposium of the British Ecological

526 Society. Oxford, Reading: Blackwell Scientific Publications, 537-555.

527 Ebensperger LA, and Cofré H. 2001. On the evolution of group-living in the new world cursorial 528 hystricognath rodents. Behavioural Ecology 12:227-236. 
529 Evanno G, Regnaut S, and Goudet J. 2005. Detecting the number of clusters of individuals using

530 the software STRUCTURE: a simulation study. Molecular Ecology 14:2611-2620.

531 Excoffier L, Smouse PE, and Quattro JM. 1992. Analysis of molecular variance inferred from

532 metric distances among DNA haplotypes - application to human mitochondrial-DNA restriction

533 data. Genetics 131:479-491.

534 Falush D, Stephens M, and Pritchard JK. 2003. Inference of population structure using multilocus

535 genotype data: Linked loci and correlated allele frequencies. Genetics 164:1567-1587.

536 Ferrand N. 1989. Biochemical and genetic studies on rabbit hemoglobin. I. Electrophoretic

537 poymorphism of the b-chain. Biochemical Genetics 27:673-678.

538 Ferrand N, and Branco M. 2007. The evolutionary history of the European rabbit (Oryctolagus

539 cuniculus): Major patterns of population differentiation and geographic expansion inferred from

540 protein polymorphism. In: Weiss S, and Ferrand N, eds. Phylogeography of European Refugia.

541 Netherlands: Springer, 207-235.

542 Ferreira C. 2012. European rabbit research in the Iberian Peninsula: state of the art and future

543 perspectives. European Journal of Wildlife Research 58:885-895.

544 Flux JEC. 1994. World distribution. In: Thompson HV, and King CM, eds. The European Rabbit

545 The History and Biology of a Successful Colonizer. Oxford: Oxford University Press, 8-21.

546 Frantz AC, Cellina S, Krier A, Schley L, and Burke T. 2009. Using spatial Bayesian methods to

547 determine the genetic structure of a continuously distributed population: clusters or isolation by

548 distance? Journal of Applied Ecology 46:493-505.

549 Fuller SJ, Wilson JC, and Mather PB. 1997. Patterns of differentiation among wild rabbit

550 populations Oryctolagus cuniculus L. in arid and semiarid ecosystems of north-eastern Australia.

551 Molecular Ecology 6:145-153.

552 Futuyma DJ. 1998. Evolutionary Biology. Sunderland: Sinauer Associates.

553 Geraldes A, Carneiro M, Delibes-Mateos M, Villafuerte R, Nachman MW, and Ferrand N. 2008.

554 Reduced introgression of the Y chromosome between subspecies of the European rabbit

555 (Oryctolagus cuniculus) in the Iberian Peninsula. Molecular Ecology 17:4489-4499. 
556 Geraldes A, Ferrand N, and Nachman MW. 2006. Contrasting patterns of introgression at X-

557 linked loci across the hybrid zone between subspecies of the European rabbit (Oryctolagus

558 cuniculus). Genetics 173:919-933.

559 Geraldes A, Rogel-Gaillard C, and Ferrand N. 2005. High levels of nucleotide diversity in the

560 European rabbit (Oryctolagus cuniculus) SRY gene. Animal Genetics 36:349-351.

561 Goudet J. 1995. FSTAT (version 1.2): A computer program to calculate F-statistics. Journal of 562 Heredity 86:485-486.

563 Guo SW, and Thompson EA. 1992. Performing the exact test of Hardy-Weinberg proportion for 564 multiple alleles. Biometrics 48:361-372.

565 Haldane JBS. 1922. Sex ratio and unisexual sterility in hybrid animals. Journal of Genetics 566 12:101-109.

567 Hardy C, Vigne J-D, Casane D, Dennebouy N, Mounolou J-C, and Monnerot M. 1994. Origin of 568 European rabbit (Oryctolagus cuniculus) in a Mediterranean island: Zooarchaeology and ancient 569 DNA examination. Journal of Evolutionary Biology 7:217-226.

570 Hardy OJ, and Vekemans X. 2002. SPAGeDi: a versatile computer program to analyse spatial 571 genetic structure at the individual or population levels. Molecular Ecology Notes 2:618-620.

572 Harrison RG. 1993. Hybrids and hybrid zones: historical perspective. In: Harrison RG, ed.

573 Hybrid zones and the evolutionary process. New York: Oxford University, 3-12.

574 Hedrick PW. 2005. Genetics of populations. Boston, MA: Jones and Bartlett.

575 Hewitt G. 1988. Hybrid zones-Natural laboratories for evolutionary studies. Trends in Ecology \& 576 Evolution 3:158-167.

577 Hoffman SMG, and Brown WM. 1995. The molecular mechanism underlying the "rare allele 578 phenomenon" in a subspecific hybrid zone of the california field mouse, Peromyscus 579 californicus. Journal of Molecular Evolution 41:1165-1169.

580 Hutchison DW, and Templeton AR. 1999. Correlation of pairwise genetic and geographic 581 distance measures: inferring the relative influences of gene flow and drift on the distribution of 582 genetic variability. Evolution 53:1898-1914. 
583 Kaeuffer R, Réale D, Coltman DW, and Pontier D. 2007. Detecting population structure using

584 STRUCTURE software: effect of background linkage disequilibrium. Heredity 99:374-380.

585 Knowles LL, and Carstens BC. 2007. Estimating a geographically explicit model of population 586 divergence. Evolution 61:477-493.

587 Loiselle BA, Sork VL, Nason J, and Graham C. 1995. Spatial genetic structure of a tropical 588 understory shrub, Psychotria officinalis (Rubiaceae). American Journal of Botany 82:1420-1425.

589 Lombardi L, Fernández N, Moreno S, and Villafuerte R. 2003. Habitat-related differences in 590 rabbit (Oryctolagus cuniculus) abundance, distribution, and activity. Journal of Mammalogy $59184: 26-36$.

592 Lovegrove BG. 1989. The cost of burrowing by the social mole rats (Bathyergidae) Cryptomys 593 damarensis and Heterocephalus glaber: the role of soil moisture. Physiological Zoology 62:449594469.

595 Lugon-Moulin N, Brunner H, Wyttenbach A, Hausser J, and Goudet J. 1999. Hierarchical 596 analyses of genetic differentiation in a hybrid zone of Sorex araneus (Insectivora: Soricidae). 597 Molecular Ecology 8:419-431.

598 Mantel NA. 1967. The detection of disease clustering and a generalized regression approach. 599 Cancer Research 27:209-220.

600 Meirmans PG. 2006. Using the AMOVA framework to estimate a standardized genetic 601 differentiation measure. Evolution 60:2399-2402.

602 Meirmans PG, and Van Tienderen PH. 2004. GENOTYPE and GENODIVE: two programs for 603 the analysis of genetic diversity of asexual organisms. Molecular Ecology Notes 4:792-794.

604 Monnerot M, Vigne JD, Biju-Duval C, Casane D, Callou C, Hardy C, Mougel F, Soriguer R, 605 Dennebouy N, and Mounolou J. 1994. Rabbit and man: genetic and historic approach. Genetics 606 Selection Evolution 26:167-182.

607 Mougel F, Mounolou J, and Monnerot M. 1997. Nine polymorphic microsatellite loci in the 608 rabbit, Oryctolagus cuniculus. Animal Genetics 28:58-71. 
609 Nei M, Maruyama T, and Chakraborty R. 1975. The bottleneck effect and genetic variability in

610 populations. Evolution 29:1-10.

611 O'Regan HJ. 2008. The Iberian Peninsula - corridor or cul-de-sac? Mammalian faunal exchange

612 and possible routes of dispersal in the last 2 million years. Quaternary Science Reviews 27:2136-

6132144.

614 Palsboll PJ. 1999. Genetic tagging: contemporary molecular ecology. Biological Journal of the

615 Linnean Society 68:3-22.

616 Pilot M, Jedrzejewski W, Branicki W, Sidorovich VE, Jedrzejewska B, Stachura K, and Funk SM.

617 2006. Ecological factors influence population genetic structure of European grey wolves.

618 Molecular Ecology 15:4533-4553.

619 Pritchard JK, Stephens M, and Donnelly P. 2000. Inference of population structure using

620 multilocus genotype data. Genetics 155:945-959.

621 Queney G, Ferrand N, Marchandeau S, Azevedo M, Mougel F, Branco M, and Monnerot M.

622 2000. Absence of a genetic bottleneck in a wild rabbit (Oryctolagus cuniculus) population

623 exposed to a severe viral epizootic. Molecular Ecology 9:1253-1264.

624 Queney G, Ferrand N, Weiss S, Mougel F, and Monnerot M. 2001. Stationary distributions of

625 microsatellite loci between divergent population groups of the European rabbit (Oryctolagus

626 cuniculus). Molecular Biology and Evolution 18:2169-2178.

627 R Core Team. 2014. R: A language and environment for statistical computing. Vienna, Austria: R

628 Foundation for Statistical Computing.

629 Raymond M, and Rousset F. 1995. GENEPOP (version 1.2) Population genetics software for 630 exact tests and ecumenicism. Journal of Heredity 86:248-249.

631 Rice WR. 1989. Analyzing tables of statistical tests. Evolution 43:223-225.

632 Richardson BJ, Hayes RA, Wheeler CM, and Yardin MR. 2002. Social structures, genetic

633 structures and dispersal strategies in Australian rabbit (Oryctolagus cuniculus) populations.

634 Behavioural Ecology and Sociobiology 51:113-121. 
635 Seixas FA, Juste J, Campos PF, Carneiro M, Ferrand N, Alves PC, and Melo-Ferreira J. 2014.

636 Colonization history of Mallorca Island by the European rabbit, Oryctolagus cuniculus, and the

637 Iberian hare, Lepus granatensis (Lagomorpha: Leporidae). Biological Journal of the Linnean

638 Society 111:748-760.

639 Shoemaker DD, and Ross KG. 1996. Effects of social organization on gene flow in the fire ant

640 Solenopsis invicta. Nature 383:613-616.

641 Smouse PE, and Peakall R. 1999. Spatial autocorrelation analysis of individual multiallele and

642 multilocus genetic structure. Heredity 82:561-573.

643 Surridge AK, Bell DJ, Ibrahim KM, and Hewitt G. 1999a. Population structure and genetic

644 variation of European wild rabbits (Oryctolagus cuniculus) in East Anglia. Heredity 82:479-487.

645 Surridge AK, Bell DJ, Rico C, and Hewitt GM. 1997. Polymorphic microsatellite loci in the 646 European rabbit (Oryctolagus cuniculus) are also amplified in other lagomorph species. Animal 647 Genetics 28:302-305.

648 Surridge AK, Ibrahim KM, Bell DJ, Webb NJ, Rico C, and Hewitt GM. 1999b. Fine-scale genetic 649 structuring in a natural population of European wild rabbits (Oryctolagus cuniculus). Molecular 650 Ecology 8:299-307.

651 van Oosterhout C, Hutchinson WF, Wills DPM, and Shipley P. 2004. MICRO-CHECKER:

652 software for identifying and correcting genotyping errors in microsatellite data. Molecular 653 Ecology Notes 4:535-538.

654 Vekemans X, and Hardy OJ. 2004. New insights from fine-scale spatial genetic structure analyses 655 in plant populations. Molecular Ecology 13:921-935.

656 Walker FM, Taylor AC, and Sunnucks P. 2007. Does soil type drive social organization in 657 southern hairy-nosed wombats? Molecular Ecology 16:199-208.

658 Webb NJ, Ibrahim KM, Bell DJ, and Hewitt GM. 1995. Natal dispersal and genetic structure in a 659 population of the European wild rabbit (Oryctolagus cuniculus). Molecular Ecology 4:239-248. 
661 Supplementary Table 1. Rabbit localities sampled in this work, number of individuals analyzed,

662 geographical coordinates and subspecies occurring in each locality according to it its natural

663 distribution range. Numbers correspond to those indicated in Fig. 1.

664 Supplementary Table 2. Genetic diversity statistics for all the rabbit localities analyzed. $\mathrm{N}=$

665 number of samples, $N_{A}=$ number of alleles, $H_{o}=$ observed heterozygosity, $H_{e}=$ expected

666 heteroygosity, $F_{I S}=$ inbreeding coefficient.

667 Supplementary Table 3. Genetic diversity statistics for the rabbit populations inferred in BAPS. N

$668=$ number of samples, $N_{A}=$ number of alleles, $H_{o}=$ observed heterozygosity, $H_{e}=$ expected

669 heteroygosity, $F_{I S}=$ inbreeding coefficient. 


\section{Table 1 (on next page)}

Genetic diversity statistics based on 10 microsatellite loci genotypes for the rabbit localities analyzed

Genetic diversity statistics based on 10 microsatellite loci genotypes for the rabbit localities ( $>=10$ individuals) analyzed and the genetic clusters inferred in BAPS. $\mathrm{n}=$ number of samples, $N_{A}=$ mean number of alleles per locus, $A_{R}=$ allelic richnes, $H_{o}=$ observed heteroyzygosity, $H_{e}=$ expected heterozygosity, $F_{I S}=$ inbreeding coefficient. The proportion of haplotypes from rabbit A and B lineages is shown for each locality and cluster. Numbers of each locality correspond to those in Fig. 1. 
Table 1. Genetic diversity statistics based on 10 microsatellite loci genotypes for the rabbit localities ( $\geq 10$ individuals) analyzed and the genetic clusters inferred in BAPS. $n=$ number of samples, $N_{A}=$ mean number of alleles per locus, $A_{R}$ = allelic richnes, $H_{o}=$ observed heteroyzygosity, $H_{e}=$ expected heterozygosity, $F_{I S}=$ inbreeding coefficient. The proportion of haplotypes from rabbit A and B lineages is shown for each locality and cluster. Numbers of each locality correspond to those in Fig. 1.

\begin{tabular}{|c|c|c|c|c|c|c|c|c|c|}
\hline Locality & $n$ & $N_{A}$ & $A_{R}$ & $H_{\circ}$ & $H_{e}$ & $F_{I S}$ & Hap A & Hap B & Subspecies \\
\hline 1. Mallorca & 14 & 6 & 5.15 & 0.63 & 0.71 & 0.15 & 0.08 & 0.92 & O. c. cuniculus \\
\hline 2. Lérida & 50 & 9.64 & 6.20 & 0.76 & 0.79 & 0.06 & 0.00 & 1.00 & O. c. cuniculus \\
\hline 3. Valencia & 18 & 9.18 & 7.13 & 0.68 & 0.80 & 0.18 & 0.06 & 0.94 & O. c. cuniculus \\
\hline 4. La Rioja & 19 & 7.00 & 5.62 & 0.72 & 0.74 & 0.06 & 0.05 & 0.95 & O. c. cuniculus \\
\hline 5. Galicia & 27 & 8.73 & 6.42 & 0.61 & 0.80 & 0.26 & 0.00 & 1.00 & O. c. cuniculus \\
\hline 6. Valladolid & 16 & 7.91 & 6.41 & 0.67 & 0.73 & 0.11 & 0.07 & 0.93 & O. c. cuniculus \\
\hline 7. Madrid1 & 51 & 12.45 & 7.70 & 0.68 & 0.86 & 0.22 & 0.40 & 0.60 & hybrid zone \\
\hline 10. Cuenca & 42 & 12.18 & 7.40 & 0.75 & 0.82 & 0.11 & 0.02 & 0.98 & hybrid zone \\
\hline 11. Toledo1 & 26 & 8.91 & 6.61 & 0.72 & 0.81 & 0.13 & 0.33 & 0.67 & hybrid zone \\
\hline 12. Toledo2 & 33 & 10.91 & 7.09 & 0.68 & 0.83 & 0.19 & 0.40 & 0.60 & hybrid zone \\
\hline 13. Toledo3 & 24 & 10.45 & 7.08 & 0.77 & 0.83 & 0.09 & 0.60 & 0.40 & hybrid zone \\
\hline 15. Toledo5 & 19 & 8.73 & 6.99 & 0.68 & 0.81 & 0.19 & 0.37 & 0.63 & hybrid zone \\
\hline 16. Toledo6 & 11 & 7.82 & 7.08 & 0.78 & 0.82 & 0.09 & 0.36 & 0.64 & hybrid zone \\
\hline 17. Ciudad Real1 & 51 & 12.36 & 7.26 & 0.69 & 0.84 & 0.19 & 0.84 & 0.16 & O. c. algirus \\
\hline 18. Ciudad Real2 & 27 & 9.73 & 7.09 & 0.64 & 0.83 & 0.25 & 0.89 & 0.11 & O. c. algirus \\
\hline 19. Ciudad Real3 & 50 & 12.27 & 7.34 & 0.70 & 0.82 & 0.16 & 0.82 & 0.18 & O. c. algirus \\
\hline 20. Albacete & 25 & 9.64 & 6.86 & 0.75 & 0.81 & 0.10 & 0.48 & 0.52 & O. c. algirus \\
\hline 21. Cáceres1 & 10 & 6.64 & 6.22 & 0.70 & 0.72 & 0.10 & 0.90 & 0.10 & O. c. algirus \\
\hline 22. Cáceres2 & 28 & 9.00 & 6.51 & 0.63 & 0.78 & 0.21 & 0.89 & 0.11 & O. c. algirus \\
\hline 23. Badajoz1 & 20 & 9.73 & 6.82 & 0.71 & 0.79 & 0.13 & 0.95 & 0.05 & O. c. algirus \\
\hline 24. Badajoz2 & 29 & 9.45 & 6.99 & 0.79 & 0.82 & 0.05 & 0.90 & 0.10 & O. c. algirus \\
\hline 25. Jaén1 & 15 & 8.64 & 6.89 & 0.63 & 0.78 & 0.23 & 0.00 & 1.00 & O. c. algirus \\
\hline 27. Jaén3 & 22 & 9.64 & 7.13 & 0.70 & 0.82 & 0.16 & 1.00 & 0.00 & O. c. algirus \\
\hline 28. Sevilla1 & 43 & 11.36 & 6.89 & 0.72 & 0.80 & 0.10 & 1.00 & 0.00 & O. c. algirus \\
\hline 29. Sevilla2 & 32 & 11.82 & 7.62 & 0.72 & 0.83 & 0.14 & 0.63 & 0.38 & O. c. algirus \\
\hline 30. Cádiz & 56 & 11.64 & 6.92 & 0.69 & 0.80 & 0.14 & 0.96 & 0.04 & O. c. algirus \\
\hline \multicolumn{10}{|l|}{ Cluster } \\
\hline K-BAL & 14 & 6.00 & 4.35 & 0.63 & 0.71 & 0.15 & 0 & 1.00 & \\
\hline K-NE & 52 & 9.55 & 5.09 & 0.74 & 0.80 & 0.07 & 0 & 1.00 & \\
\hline $\mathrm{K}-\mathrm{N}$ & 21 & 7.00 & 4.61 & 0.69 & 0.74 & 0.10 & 0 & 1.00 & \\
\hline $\mathrm{K}-\mathrm{CU}$ & 14 & 6.73 & 4.99 & 0.69 & 0.74 & 0.13 & 0.07 & 0.93 & \\
\hline $\mathrm{K}-\mathrm{ZH}$ & 457 & 21.00 & 6.20 & 0.70 & 0.87 & 0.20 & 0.49 & 0.52 & \\
\hline K-S1 & 206 & 16.36 & 5.72 & 0.71 & 0.83 & 0.14 & 1.00 & 0.00 & \\
\hline
\end{tabular}

$F_{\text {IS }}$ values in bold represent significant deviations form Hardy-Weinberg equilibrium, after Bonferroni correction. 


\section{Table 2 (on next page)}

Proportion of mitochondrial lineage and average assignment probabilities for each locality to the genetic populations inferred.

Proportion of lineage $A$ and $B$ rabbits and average assignment probability of each locality to the populations inferred in STRUCTURE and BAPS. Numbers of each locality correspond to those in Fig. 1. 
Table 2. Proportion of lineage A and B rabbits and average assignment probability of each locality to the populations inferred in STRUCTURE and BAPS. Numbers of each locality correspond to those in Fig. 1.

\begin{tabular}{|c|c|c|c|c|c|c|c|c|c|c|c|c|}
\hline \multirow[b]{3}{*}{ Locality } & \multirow{3}{*}{$n$} & \multicolumn{2}{|l|}{ mtDNA } & \multicolumn{2}{|c|}{ STRUCTURE } & \multirow{3}{*}{$\begin{array}{l}\text { BAPS } \\
\text { K-BAL }\end{array}$} & \multirow{3}{*}{ K-NE } & \multirow{3}{*}{ K-N } & \multirow{3}{*}{$\mathrm{K}-\mathrm{CU}$} & \multirow{3}{*}{ K-ZH } & \multirow{3}{*}{ K-S1 } & \multirow{3}{*}{$\mathrm{K}-\mathrm{S} 2$} \\
\hline & & Hap A & Hap B & K1 & K2 & & & & & & & \\
\hline & & & & & & & & & & & & \\
\hline 1. Mallorca & 14 & 0.08 & 0.92 & 0.09 & 0.91 & 1.00 & & & & & & \\
\hline 2. Lérida & 50 & & 1.00 & 0.04 & 0.96 & & 0.98 & & & 0.02 & & \\
\hline 3. Valencia & 18 & 0.06 & 0.94 & 0.26 & 0.74 & & 0.11 & & & 0.89 & & \\
\hline 4. La Rioja & 19 & 0.05 & 0.95 & 0.06 & 0.94 & & & 0.95 & & 0.05 & & \\
\hline 5. Galicia & 27 & & 1.00 & 0.44 & 0.56 & & & & & 0.89 & 0.11 & \\
\hline 6. Valladolid & 16 & 0.07 & 0.93 & 0.19 & 0.82 & & 0.06 & & & 0.88 & 0.06 & \\
\hline 7. Madrid1 & 51 & 0.40 & 0.60 & 0.38 & 0.62 & & & 0.02 & & 0.75 & 0.24 & \\
\hline 8. Madrid2 & 7 & 0.29 & 0.71 & 0.06 & 0.94 & & & 0.29 & & 0.71 & & \\
\hline 9. Madrid3 & 2 & 1.00 & & 0.15 & 0.85 & & & & & 1.00 & & \\
\hline 10. Cuenca & 42 & 0.02 & 0.98 & 0.12 & 0.88 & & & & 0.33 & 0.67 & & \\
\hline 11. Toledo1 & 26 & 0.33 & 0.67 & 0.23 & 0.77 & & & & & 1.00 & & \\
\hline 12. Toledo2 & 33 & 0.40 & 0.60 & 0.19 & 0.81 & & & & & 1.00 & & \\
\hline 13. Toledo3 & 24 & 0.60 & 0.40 & 0.16 & 0.84 & & & & & 1.00 & & \\
\hline 14. Toledo4 & 2 & & 1.00 & 0.08 & 0.92 & & & & & 1.00 & & \\
\hline 15. Toledo5 & 19 & 0.37 & 0.63 & 0.16 & 0.84 & & & & & 1.00 & & \\
\hline 16. Toledo6 & 11 & 0.36 & 0.64 & 0.21 & 0.79 & & & & & 1.00 & & \\
\hline 17. Ciudad Real1 & 51 & 0.84 & 0.16 & 0.67 & 0.33 & & & & & 0.92 & 0.08 & \\
\hline 18. Ciudad Real2 & 27 & 0.89 & 0.11 & 0.47 & 0.53 & & & & & 0.96 & 0.04 & \\
\hline 19. Ciudad Real3 & 50 & 0.82 & 0.18 & 0.66 & 0.35 & & & & & 0.96 & 0.04 & \\
\hline 20. Albacete & 25 & 0.48 & 0.52 & 0.16 & 0.84 & & & & & 1.00 & & \\
\hline 21. Cáceres1 & 10 & 0.90 & 0.10 & 0.70 & 0.30 & & & & & 0.70 & 0.30 & \\
\hline 22. Cáceres2 & 28 & 0.89 & 0.11 & 0.60 & 0.40 & & & & & 0.89 & 0.11 & \\
\hline 23. Badajoz1 & 20 & 0.95 & 0.05 & 0.92 & 0.09 & & & & & 0.05 & 0.95 & \\
\hline 24. Badajoz2 & 29 & 0.90 & 0.10 & 0.94 & 0.06 & & & & & 0.03 & 0.97 & \\
\hline 25. Jaén1 & 15 & & 1.00 & 0.52 & 0.48 & & & & & 0.50 & 0.50 & \\
\hline 26. Jaén2 & 2 & 0.93 & 0.07 & 0.87 & 0.14 & & & & & 0.47 & 0.53 & \\
\hline 27. Jaén3 & 22 & 1.00 & & 0.82 & 0.18 & & & & & 0.82 & 0.18 & \\
\hline 28. Sevilla1 & 43 & 1.00 & & 0.91 & 0.09 & & & & & 0.02 & 0.98 & \\
\hline 29. Sevilla2 & 32 & 0.63 & 0.38 & 0.86 & 0.14 & & & & & 0.03 & 0.75 & 0.22 \\
\hline 30. Cádiz & 56 & 0.96 & 0.04 & 0.91 & 0.09 & & & & & 0.09 & 0.91 & \\
\hline \multicolumn{13}{|l|}{ Population } \\
\hline K-BAL & 14 & & 1.00 & 0.09 & 0.91 & & & & & & & \\
\hline K-NE & 52 & & 1.00 & 0.04 & 0.96 & & & & & & & \\
\hline $\mathrm{K}-\mathrm{N}$ & 21 & & 1.00 & 0.05 & 0.95 & & & & & & & \\
\hline $\mathrm{K}-\mathrm{CU}$ & 14 & 0.07 & 0.93 & 0.06 & 0.94 & & & & & & & \\
\hline $\mathrm{K}-\mathrm{ZH}$ & 457 & 0.49 & 0.52 & 0.37 & 0.63 & & & & & & & \\
\hline K-S1 & 206 & 0.90 & 0.10 & 0.93 & 0.06 & & & & & & & \\
\hline K-S2 & 7 & 1.00 & & 0.89 & 0.11 & & & & & & & \\
\hline
\end{tabular}




\title{
Table 3 (on next page) \\ AMOVA analyses
}

\begin{abstract}
AMOVA analysis performed for different levels of genetic structure among the rabbit localities analyzed and the inferred clusters.
\end{abstract}


Table 3. AMOVA analysis performed for different levels of genetic structure among the rabbit localities analyzed and the inferred clusters.

\begin{tabular}{|c|c|c|c|c|c|c|c|c|}
\hline \multicolumn{9}{|c|}{$\%$} \\
\hline & Structure & variation & & $F^{\prime}$ & $p$ & & $R$ & $p$ \\
\hline \multicolumn{9}{|l|}{ Localities } \\
\hline & All localities & 0.287 & $F_{S T^{\prime}}$ & 0.37 & 0.001 & $R_{S T}$ & 0.11 & 0.001 \\
\hline & A Haplotypes Vs. B Haplotypes & 0.111 & $F_{S T^{\prime}}$ & 0.173 & 0.001 & $R_{S T}$ & 0.637 & 0.001 \\
\hline \multicolumn{9}{|l|}{ Clusters } \\
\hline & STRUCTURE K1 Vs. K2 & 0.192 & $F_{S T^{\prime}}$ & 0.26 & 0.001 & $R_{S T}$ & 0.635 & 0.001 \\
\hline & All clusters BAPS & 0.253 & $F_{S T^{\prime}}$ & 0.325 & 0.001 & $R_{S T}$ & 0.627 & 0.001 \\
\hline
\end{tabular}




\section{Figure 1}

Maps of the Iberian Peninsula indicating the rabbit localities analyzed

Maps of the Iberian Peninsula indicating the localities analyzed (numbers correspond to localities in Supplementary Table 1), the hybrid zone (white dotted line), the perpendicular transect (black dotted line) and the average individual assignment probabilities for the 7 clusters inferred in BAPS. Colour gradient from grey (or green) to white denotes assignment probabilities for each population from 0 to 1 . 

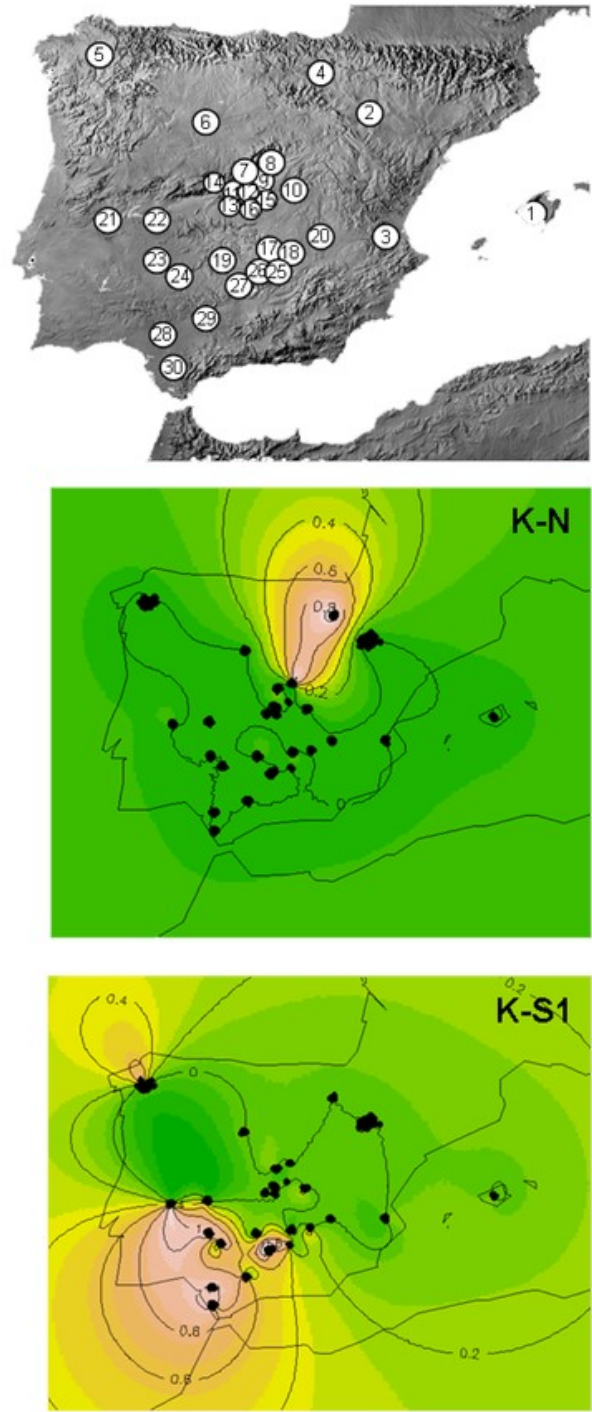
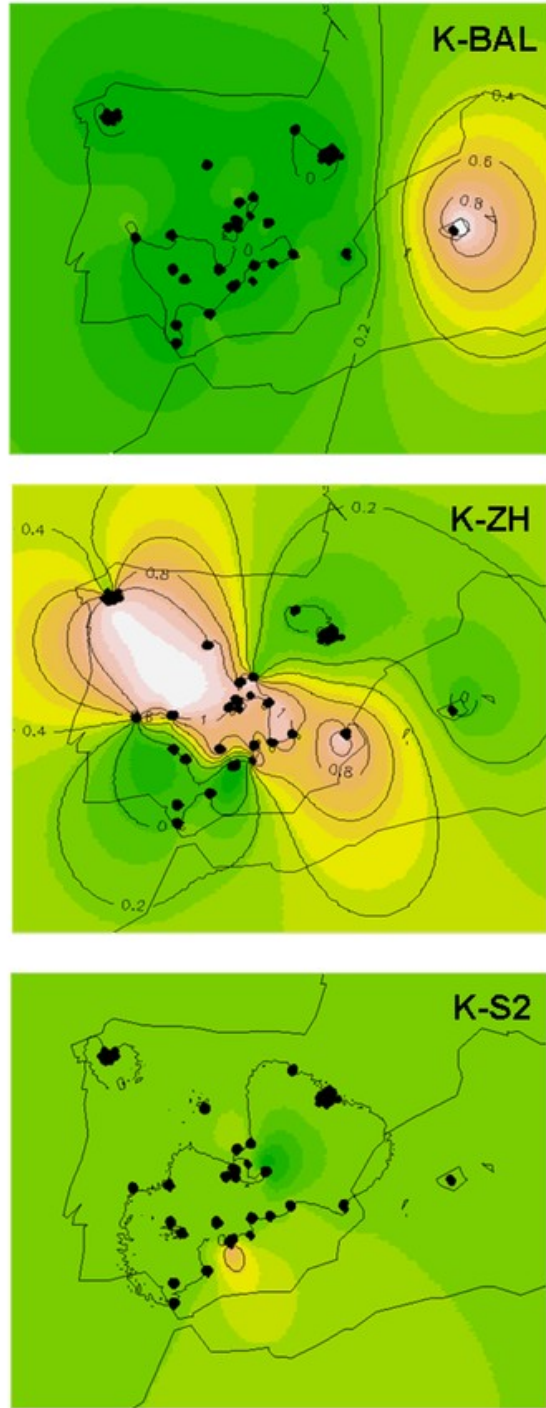
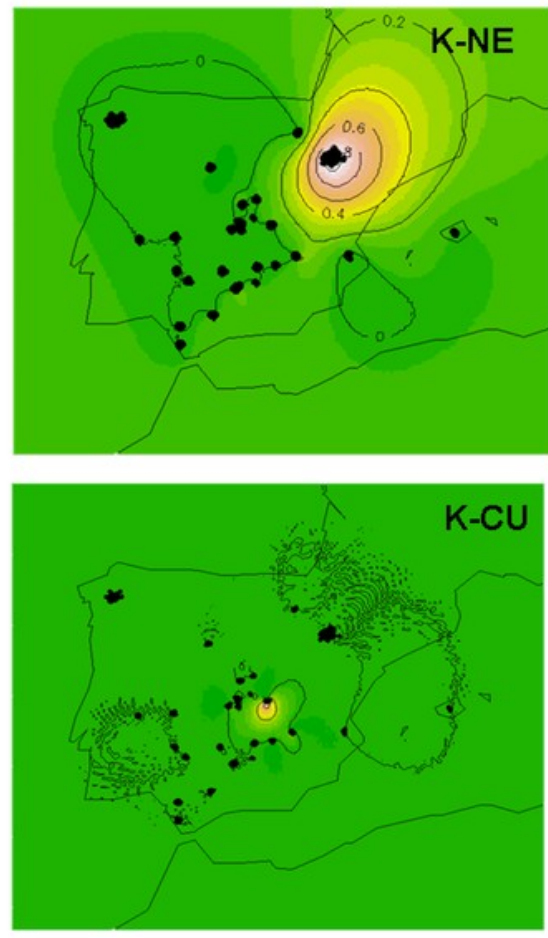


\section{Figure 2}

Individual assignment probabilities to the genetic groups inferred in STRUCTURE.

Individual assignment probabilities $(q)$ to genetic group K1 (A). Each dot represents an individual, and grey bars are the confidence intervals obtained for their assignment probabilities. Dotted lines indicate assignment probabilities to group K1 larger than 0.9 and lower than 0.1. The number of individuals assigned within these intervals and the proportion of their mitochondrial lineages are indicated. 


\section{Figure 3}

Clinal patterns for the mitochondrial and nuclear markers along the rabbit hybrid zone.

Clinal patterns for the mitochondrial (grey lines) and nuclear markers (black lines) along the hybrid zone transect from southwestern to northeastern Spain (see Fig. 1). Dots represent the frequency of lineage A mitochondrial haplotypes (grey) and mean assignment probabilities $(q)$ to genetic group K1 (A) in each locality. Distances are in km, starting (km 0) at the intersection between the transect and the hybrid zone. Negative distance values indicate $\mathrm{km}$ to the south and positive values $\mathrm{km}$ to the north. 


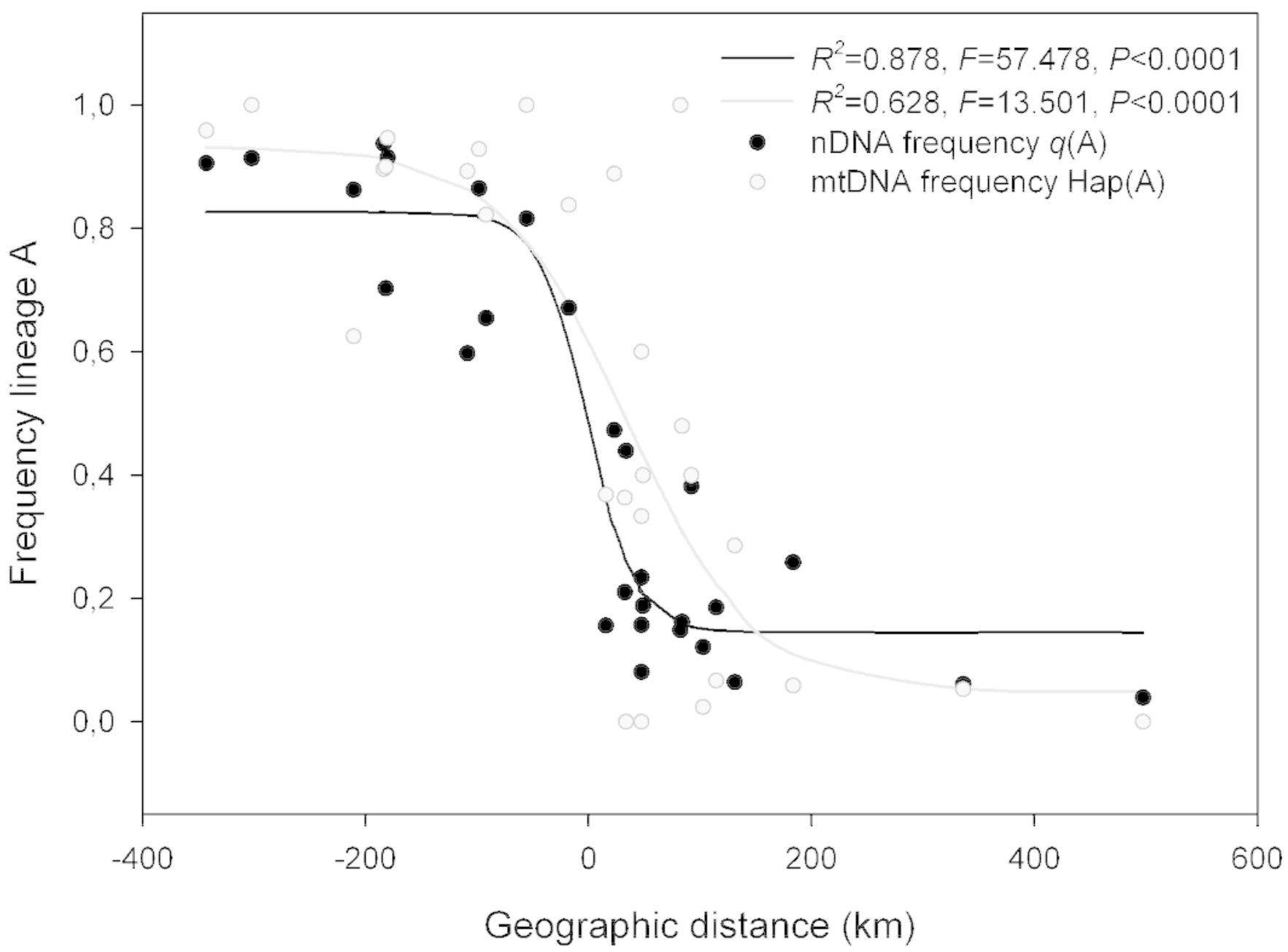




\section{Figure 4}

Isolation by distance among rabbit localities

Isolation by distance for all the localities of $O$. cuniculus analyzed, as shown by the correlation of genetic distances $\left(F_{S T} / 1-F_{S T}\right)$ and geographic distances (Mantel test).

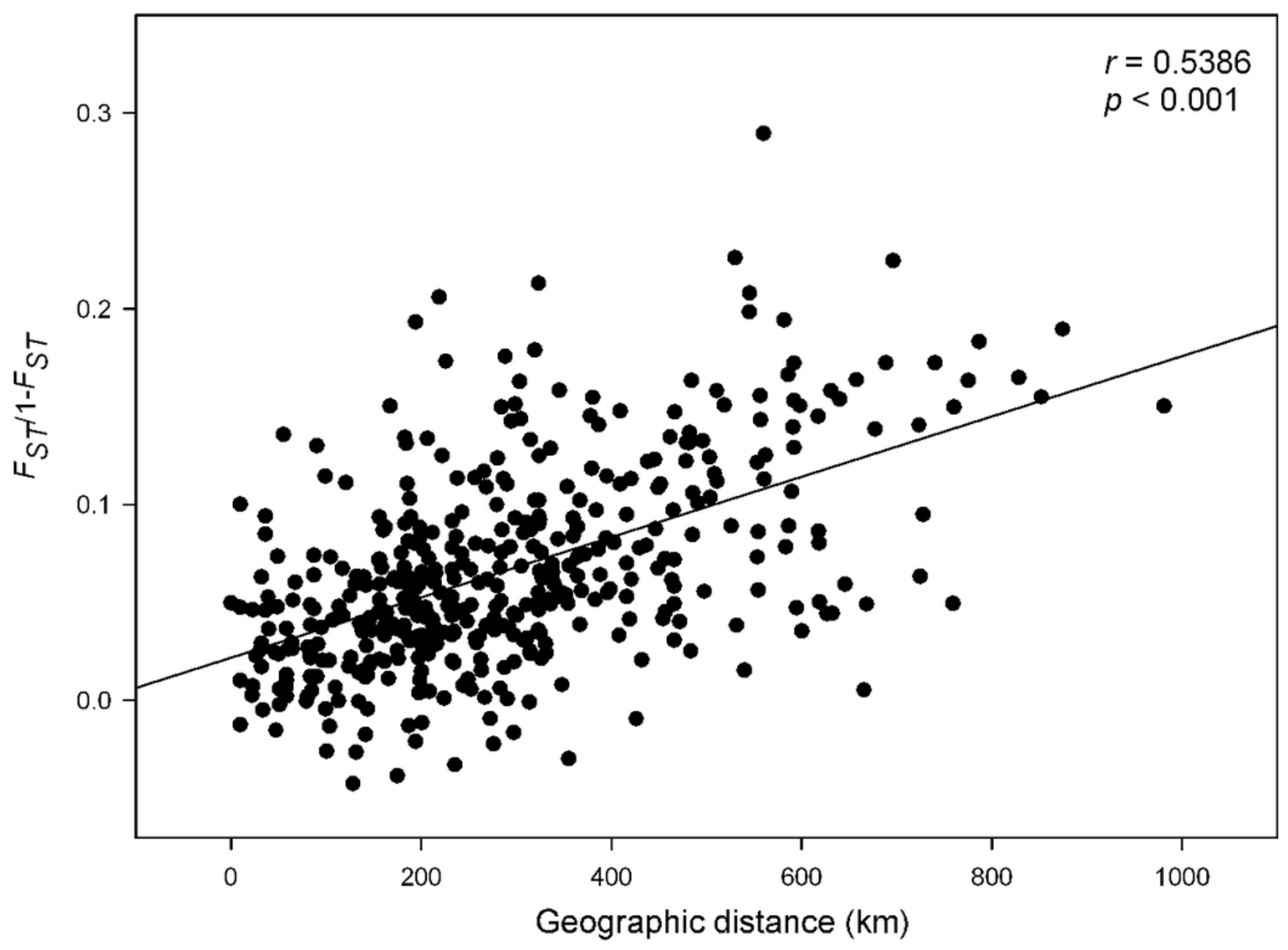




\section{Figure 5}

Spatial autocorrelation analyses

Spatial autocorrelation analyses showing the average inbreeding coefficient $\left(f_{i j}\right)$ for each distance interval among individuals $\left(d_{i j}\right)$, for the complete dataset $(\mathrm{A})$ and for each of the subspecies analyzed and the hybrid zone separately (B). Black symbols represent significant correlations between $f_{i j}$ and $d_{i j}$ 

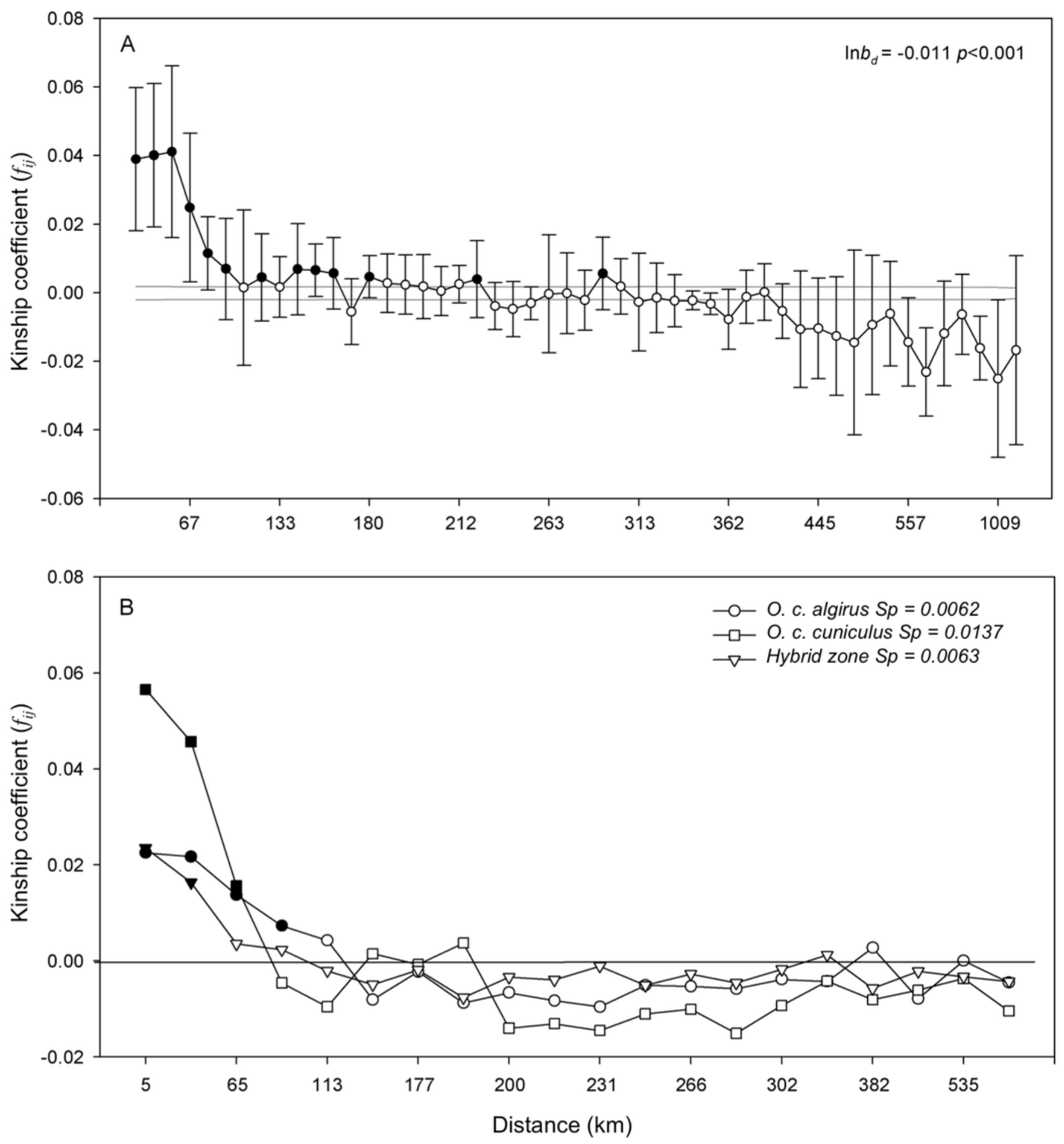